\title{
A enciclopédia de Arthur Bispo do Rosário
}

\author{
Maria Esther Maciel
}

\section{Resumo}

O trabalho analisa o conjunto da obra de Arthur Bispo do Rosário, tomando-a como uma espécie de "enciclopédia" híbrida e em afinidade dissonantes com os modelos enciclopédicos legitimados no mundo europeu. Uma enciclopédia que se configura como uma intrincada rede de saberes sobre as coisas do mundo e que não prescinde de referências afro-americanas, elementos da cultura popular do nordeste, motivos náuticos e alusóes à cultura contemporânea do descartável. Nela, o gesto taxonômico está a serviço de uma ordenação que acaba por revelar em seus excessos uma desordem intrínseca, a qual, por sua vez, não reflete senão a impossibilidade de o mundo ser representado como um sistema suficiente e definitivo.

Palavras-chave: Arthur Bispo do Rosário; arte contemporânea; enciclopédia

\footnotetext{
Abstract

This paper focuses on the artworks of Arthur Bispo do Rosário, taking them as components of a kind of hybrid encyclopedia, in dissonant affinities with the legitimated encyclopedic models of the European culture. My purpose is to show how Bispo's "encyclopedia" is configured as an intricate web of different sorts of knowledge about the things of the world, which includes Afro-american references, elements taken from the Brazilian popular culture, nautical knowledge, and allusions to contemporary culture of the disposable things. In it, the taxonomic procedures are used to reveal an order that, in its excess, brings an intrinsic disorder that reflects our impossibility to satisfactorily represent the world
} 


\section{outraTravessia}

as a definite and sufficient system.

Key-words: Arthur Bispo do Rosário; contemporary art; encyclopedia

No imaginário reside o infinito

(Maurice Blanchot)

O mundo, na soma infinita de suas coisas possíveis e impossíveis, foi o que o artista sergipano Arthur Bispo do Rosário (1909-1989) buscou inventariar ao longo de sua vida, movido pela crença de que teria recebido de Deus essa missão. Sua aspiração à exaustividade, aliada ao fervor com que conduziu a tarefa de catalogação de todo o "material existente na terra dos homens", levou-o à construção de uma obra multíplice, na qual reuniu não apenas tudo (ou quase tudo) que acreditava ser necessário para a reinvenção do mundo após o Juízo Final, como também registros e dejetos de um tempo, um lugar e uma história de vida. Compôs, dessa forma, uma espécie de enciclopédia pessoal, afinada com as exigências de ordem inerentes a todo projeto enciclopédico e, ao mesmo tempo, aberta à desordem criativa da memória e da imaginação.

Tomar a obra de Bispo como enciclopédica é reconhecê-la como uma intrincada rede de saberes sobre as coisas do mundo, na qual a totalidade se evidencia como um conjunto sempre inacabado e fragmentário, apesar das pretensóes de completude e exaustividade que norteiam a sua concepção. Nela, o gesto taxonômico está a serviço de uma ordenação que acaba por revelar em seus excessos uma desordem intrínseca, a qual, por sua vez, não reflete senão a impossibilidade de o mundo ser representado como um sistema suficiente e definitivo. Em outras palavras, o inventário de Bispo, em suas íntimas tensões entre ordem e desordem, evidencia - ainda que involuntariamente - tanto o caráter inesgotável e fragmentário do que busca representar, quanto o caráter arbitrário dos sistemas classificatórios que, em nome da cientificidade, foram e têm sido construídos para categorizar de forma racional a multiplicidade das coisas e conhecimentos do mundo. Pode-se dizer, inclusive, que tal revelação involuntária advém, em certa medida, da própria loucura do artista. Já não disse Foucault que o "saber dos loucos" anuncia "a trágica loucura do mundo"(FOUCAULT, 2005, p. 28) ?

Listar e classificar meticulosamente todos os objetos, nomes, bordados, coleções, inscrições, restos de coisas descartáveis, descrições de utensílios, desenhos, referências geográficas, náuticas e onomásticas de Arthur Bispo torna-se um trabalho quase tão difícil quanto a tarefa a que ele se dedicou durante a maior parte da vida. Isso, porque seu inventário - ao se furtar aos critérios de seletividade necessários à montagem de uma enciclopédia convencional - abre-se ao excessivo e ao incontrolável, num processo que Umberto Eco, na esteira de Peirce, chamou de "semiose ilimitada" ${ }^{2}$

1 Arthur Bispo do Rosario em entrevista a Hugo Denizard. Apud HIDALGO, 1996, p. 139.

2 Atento exatamente ao que chamou de "natureza incontrolável", múltipla, de tal modelo, Umberto Eco desenvolveu toda uma teoria em torno da idéia de enciclopédia - dotada, segundo ele, de uma "semiose ilimitada" - e comparoua a um labirinto extensivel ao infinito. Segundo ele, a enciclopédia, ao contrário do que postularam os enciclopedistas franceses, não reflete de modo unívoco e racional um universo ordenado, mas fornece regras, "em geral míopes", para que, "segundo algum critério provisório de ordem", se busque dar sentido a um mundo desordenado ou cujos critérios de ordem nos escapam. E nesse sentido, tal modelo destoaria do de dicionário, por excluir definitivamente, 
Se tomarmos, por exemplo, os fichários de pano do artista, encontraremos não apenas nomes de coisas, mas também referências funcionais e utilitárias dos artefatos listados, marcas comerciais, indicações de cores, tamanhos, espessuras, quantidades e qualidades dos objetos, tudo numericamente discriminado, como se pode ver no seguinte fragmento:

10.033. Bolça pintada de vernis preta 24 por 20 .

4.027. folha de flandres $16 \mathrm{cms}$, liso no centro e furado nos extremos

690. pratos de papelão para doce com frisado

12.026 - modes livre absorvente para uso das moças marca Johnson

10.016. calça cor bege pra mulher de luxo

13.018. caixas palitos para usar em cima de mesa restaurante pensão hotel

11.012. sabonete cinta azul perfumado usado no banho

13. 021. abridor tampa garrafa - coca-cola fanta crush soda água

7.011. pastas dental - molhe a escova água bote um poco de creme esfregue nos dentes

13.02. espelhos pequenos para usar nos dias de festa de reis

12.012. porta seios para moça - marca millus

8.02. suporte para proteger vidro do holofote

570. papel entre duas páginas limpas - escreva com lápis

12.017. sandalia cor castanho de couro - sola de borracha

8.027. retalhos de pano com varias cores tipos 3

Isso, para não mencionar as inúmeras inscrições e figuras bordadas em estandartes, faixas e roupas, ou as anotações e listas feitas em pedaços de papelão, madeira e plástico. Mesmo que se diga que o acervo de Bispo contém em torno de mil peças, este número não comporta a variedade e quantidade dos objetos, símbolos e escritos que cada um desses mil itens comporta. Qual seria a soma dos botóes, moedas, tampinhas, fichas, bugigangas, penduricalhos, bandeiras, talheres, sapatos e sandálias, miniaturas de navios, navios bordados, ferramentas que constituem as coleções heterogêneas do artista sergipano?

Basta um olhar sobre suas assemblages - ou "vitrines", como ele mesmo as denominava - para que se constate o caráter inumerável e por vezes insólito desses ajuntamentos de coisas, os quais poderiam ser, até mesmo, associados a "pranchas" enciclopédicas. O que se justifica pelos surpreendentes traços de afinidade que tais assemblages mantêm com as pranchas ilustrativas que integraram a Enciclopédia Francesa - no caso, gravuras com desenhos de objetos, utensílios, máquinas, gráficos, listas, organizados como uma espécie de "estrutura de informações" sobre o mundo material - e ainda por suas características enquanto "grande tábua, grossa e larga", "bloco de

"a possibilidade de hierarquizar de modo único e incontroverso as marcas semânticas, as propriedades, os semas", assumindo, ao contrário, a função de mapear a vida de uma cultura como um sistema de sistemas intersemióticos interligados. Cf. ECO, 1991, pp. 336-337. Ver também: MACIEL, 2004, pp.13-26.

3 Anotação feita por Ricardo Maciel dos Anjos Cardoso, no Museu Oscar Niemayer (Curitiba), onde foi realizada uma exposição de trabalhos de Arthur Bispo do Rosário, em maio de 2005. 
madeira, inteiriço ou formado de várias peças solidamente coladas", que, segundo o Dicionário Aurélio, também recebe o nome de "prancha". ${ }^{4}$

Pode-se dizer que, à feição das pranchas da Encyclopédie, que como se sabe, ocuparam 11 dos 35 volumes publicados entre 1751 e 1772, sob direção de Diderot e D'Alembert, as "vitrines" de Bispo apresentam um recenseamento pormenorizado dos objetos e compóem o que Roland Barthes, num ensaio de 1964, chamou de "uma certa epopéia da matéria." (BARTHES, 1974, p.35). Nesse sentido, a elas se aplicariam as palavras de Barthes sobre as pranchas francesas, as quais, segundo ele, "abrangem toda a esfera das matérias a que o homem empresta uma forma: roupas, veículos, utensílios, armas, instrumentos, móveis, tudo que o homem recorta na madeira, no metal, no vidro e na fibra é aí catalogado, do cinzel à estátua, da flor artificial ao navio" (BARTHES, 1974, p. 28).

Mas à diferença dos enciclopedistas do Iluminismo, Bispo não estriba as suas pranchas num conjunto sistemático de critérios seletivos e ordenadores, com fins didáticos e ilustrativos. Se as pranchas da Encyclopédie, como nos lembra Barthes, são movidas pelo "excesso de razão" e partem de uma "severa exigência de objetividade", ainda que atravessadas pelas "vibrações infinitas do sentido", as de Bispo levam ao extremo o abalo do "universo exato" que aquelas tomam como ponto de partida. Enquanto na iconografia da Encyclopédie as vibraçóes do sentido tendem a uma certa unidade, sugerindo "um sentido último", as pranchas de Bispo afirmam-se como um transbordamento poético dos sentidos, entrando na ordem do dispêndio. Além disso, o recenseamento e a definição - princípios que, segundo Barthes, constituem a prática enciclopédica advêm, no caso, de um saber não legitimado socialmente, fora da ordem canônica da cultura erudita e, portanto, em estado de deslocamento, de novidade e de alteridade radical em relação ao modelo iluminista.

Todas as referências náuticas, por exemplo, que aparecem nos trabalhos do artista sergipano em forma de imagens, artefatos, inscriçóes, listas de tipos de navios, nomes de fragatas e tripulantes, são extraídas de sua vivência como marinheiro, e prescindem dos tratados científicos de náutica e navegação ${ }^{5}$. Aliás, o ofício de sinaleiro de navios, exercido após o de grumete, foi importante para que Bispo adquirisse conhecimentos sobre bandeiras e emblemas de estados e nações, como relata Luciana Hidalgo na biografia do artista (HIDALGO, 1996, p.77). As viagens que fez pelo país (segundo a pesquisadora, não há registros de trajetos internacionais) datam do período entreguerras, de 1925 a 1933. Daí que muitos dos trabalhos de Bispo incluam uma vasta iconografia referente às embarcações da Marinha dos anos 20 e 30 , em suas variações e particularidades. Para não mencionar a impressionante profusão de dados toponímicos

4 A palavra "prancha", segundo o Dicionário Aurélio, designa ainda um "tipo de embarcação fluvial, provida de velas triangulares".

5 Luciana Hidalgo conta que Bispo foi levado à Escola de Aprendizes pelas mãos do pai aos 15 anos, em 1925, e completa: "Ali Bispo ficou durante um ano, e de aprendiz virou grumete, desembarcando no porto do Rio de Janeiro em 1926. Arthur Bispo do Rosario era então o número 15148 do Quartel Central do Corpo de Marinheiros Nacionais Villegaignon. Embarcado $\mathrm{e}$ afogado em estreitos códigos de honra, Bispo tinha de dançar conforme a música marítima. Uma época dura, regida por uma trinca de exigências: espírito de disciplina, respeito à hierarquia e ardor patriótico. Vida de marinheiro era levada no mar. Uma rotina sobrecarregada de deveres, restriçōes e olhares militares à espreita do desvio." HIDALGO, 1986, p. 76. 
e geográficos que integra o universo do autor, através de nomes de países, ilhas, cidades, portos, espaços urbanos, logradouros, etc.

Nesse sentido, pode-se afirmar que a enciclopédia de Bispo incorpora o que os enciclopedistas franceses excluíram de seu projeto com o propósito de torná-lo exeqüível: as redundâncias, os restos, os saberes e coisas inclassificáveis, a matéria-prima da experiência vital, os registros das margens, enfim, tudo o que poderia ser colocado sob o rótulo abrangente e impreciso do "et cetera". Daí que ela se aproxime menos das enciclopédias sistematizadas da era moderna do que dos modelos enciclopédicos anteriores ao século XVIII (em especial o de viés renascentista) e das obras enciclopédicas de escritores e artistas contemporâneos, como Jorge Luis Borges, Italo Calvino, Georges Perec, Umberto Eco e Peter Greenaway, que criaram, cada um à sua maneira, verdadeiros anti-sistemas de ordenação, abalando - seja pelas leis paródicas da ficção, seja pelos princípios desestabilizadores da poesia - a própria lógica taxonômica que os define enquanto "inventários do mundo". 6

Interessante que no famoso "Discours préliminaire" que abre o primeiro volume da Encyclopédie o próprio D'Alembert tenha admitido as limitações de seu projeto, reconhecendo que o sistema universal dos saberes é "uma espécie de labirinto, um caminho tortuoso" (D'ALEMBERT, 2007), e que o modelo mais propício para a organização do sistema geral de todo esse conhecimento seria o do mapa multidimensional. Mas pondera, por outro lado, que a desordem labiríntica "desfiguraria, ou pelo menos aniquilaria de todo uma árvore enciclopédica na qual se quisesse representá-la". Daí ser necessário, segundo ele, "dar a cada parte uma extensão conveniente, insistir sobre o essencial, negligenciar as minúcias e evitar um defeito assaz comum que consiste em dar peso àquilo que só precisa de uma palavra, provar o que ninguém contesta, comentar o que é claro" (D'ALEMBERT, 2007). Sob esse prisma, a Encyclopédie só poderia se concretizar como uma versão reduzida, uma tradução limitada - e definida por determinadas regras de razoabilidade - do sistema labiríntico de saberes sobre o mundo.

Já a ilusão de que seria possível uma tradução exaustiva desse labirinto foi o que marcou a prática enciclopédica nos séculos anteriores ao advento da modernidade iluminista, mais especificamente nos séculos XVI e XVII, quando os princípios taxonômicos ainda não apresentavam o rigor científico que adquiriram a partir do triunfo do logos moderno. A enciclopédia, portanto, era vista como um espesso e intrincado conjunto de referências, supostamente capaz de abarcar e exaurir toda a camada de signos depositada sobre as coisas.

É importante lembrar que o termo "enciclopédia" foi usado pela primeira vez no século XVI, embora só a partir do séc. XVII tenha adquirido o sentido que hoje lhe atribuímos.(POMBO, 2006, p. 180). A prática enciclopédica no Ocidente, contudo, é bem mais antiga, remontando à Grécia tardia, mais especificamente à obra de Aristóteles (ainda que se fale também de Speusippo (393-339 a.C., sobrinho de Platão), possuindo, sobretudo, fins educativos. Já no mundo romano, o enciclopedismo toma a forma de um trabalho de compilação e balanço dos conhecimentos de uma época em processo de decadência, como explica a estudiosa portuguesa Olga Pombo. Varrão e, sobretudo,

6 Essa questão foi desenvolvida em vários ensaios do livro A memória das coisas. Cf. MACIEL, 2004. 
Plínio, o Velho, seriam os nomes medulares dessa época, sendo que a Historia Naturalis de Plínio destaca-se como a grande enciclopédia do mundo antigo, cujo propósito principal era registrar e acumular exaustivamente "toda a espécie de informações, fatos, detalhes e curiosidades relativas ao mundo físico". Exaustividade esta que também se dá a ver no mundo medieval e que se prolonga, enquanto compilação de coisas, palavras, imagens, narrativas e discursos que compõem a densa complexidade do mundo, no Renascimento e na passagem para a época barroca. Verifica-se aí, segundo Pombo, "uma abundância excessiva de materiais, no caso do Renascimento, informativos mas caóticos, no caso do século XVII". (POMBO, 2006, p. 202) ${ }^{7}$

Figuras como Giulio Camillo (1480-1544), Ulisse Aldrovandi (1522-1605) e Athanasius Kircher (1602-1680) são representantes por excelência dessa prática enciclopédica voltada para a construção de inventários do mundo, a partir de critérios taxonômicos instáveis oriundos de um amálgama entre "saber racional, noções derivadas de práticas de magia e de toda uma herança cultural, cujos poderes de autoridade a redescoberta de textos antigos havia multiplicado", para usar aqui as palavras de Foucault (FOUCAULT, 1987, p. 48) sobre o período renascentista, quando a racionalidade não prescindia do gosto pelo extraordinário nem da vertigem da exaustividade.

No caso de Camillo, sabe-se que criou um projeto chamado "Teatro da Memória" - um edifício transportável feito de madeira, espécie de anfiteatro, no qual o espectador poderia visualizar, a partir de um ponto, tudo o que existe na terra, através de imagens, símbolos e citaçóes. ${ }^{8}$ Já no que se refere a Aldrovandi, sua pulsão colecionadora o levou a fazer de seus gabinetes de curiosidades uma monumental enciclopédia de objetos e cerca de 8 mil desenhos. Seu intento, como explicou Philipp Blom, era "concluir o que Aristóteles e Plínio começaram: uma enciclopédia da natureza" (BLOM, 2003, p.31). Para tanto, transformou sua coleção em um mostruário inextricável de animais e coisas do mundo natural, acompanhado de descrições exatas e fantasiosas sobre a anatomia, o habitat, as superstições, os usos das espécies zoológicas. Kircher, por sua vez, um padre jesuíta alemão que era versado em filosofia, física, egiptologia, arquitetura, matemática, filologia, alquimia, cabala, teosofia e astronomia, criou um projeto transdisciplinar de um sistema universal do conhecimento, chegando mesmo a inventar uma máquina de metáforas, espécie de "fábrica de imagens e metamorfoses", descrita por Gustave Hocke da seguinte maneira:

Debaixo de um espelho, escondido sob um móvel em forma de baú, enxerga-se um cilindro contendo diversas imagens. Quando

7 Como explica Olga Pombo: "A maior tradição enciclopedista é, como seria de esperar, a italiana de que se destacam os seguintes titulos: os Fons memorabilium universi de Domenico Bandini (1335.1418), os De expetendis et fugiendis rebus (1501) de Giorgio Valla (1430-1500), 49 livros que reúnem, de forma mais ou menos caótica, elementos díspares sobre os mais variados assuntos (Filosofia, aritmética, música, geometria, astrologia, mecânica, astrologia, fisica e metafísica, medicina, gramática, dialéctica, poética, retórica, filosofia moral, economia doméstica, políica, bens e males da alma e do corpo, glória, poder, fama, etc.Cf. os Commentariorum Urbanorum (1506) de Rafaele Maffei (1451-1522), o Summarto di tutte scienze (1556) de Domenico Delfino ou o Speccbio di scienza universale de Leonardo Fioravanti (1564). Em França, o Dictionarium bistoricum, geographicum et poeticum (1553) de Charles Estienne (1504-1564) é a obra de maior relevância". Cf. POMBO, 2006.,p.202.

8 Segundo Hooper-Greehill, citada por Durval Lara Filho, o termo "teatro", na época, "era usado no sentido de compilação, coleção ou compêndio sobre algum tema”. CE. LARA FILHO, 2005, p. 21, nota 20. 
o visitante se olha no espelho colocado sobre o móvel, ele recebe várias formas: sol, animal, esqueleto, planta ou pedra. Tudo é comparável a tudo. (HOCKE, 1986, p.199)

Kircher, também artista, criou pranchas nas quais buscava representar várias ordens dos saberes, através de desenhos detalhados de labirintos, mapas, árvores do conhecimento, pirâmides, construções arquitetônicas (como a "Torre de Babel" e a "Arca de Noé”.), mandalas, horóscopos, máquinas, partituras musicais, obeliscos, planetas, séries de animais e objetos, dentre outras coisas. Além disso, foi um colecionador de artefatos antigos e animais dissecados. Não à toa elegeu como princípio a frase: "nada é mais belo do que saber tudo".(GODWIN, 1979, p.9)

Não seria de todo absurdo dizer, diante de tais experiências, que é a essa linhagem de enciclopedistas delirantes que se filia Arthur Bispo do Rosário. Ao criar o seu próprio "teatro do mundo", o artista sergipano exercitou um enciclopedismo iluminado, que funda os seus próprios princípios de ordenação ao mesmo tempo que se abre àquilo que Philipp Blom chamou de "caóticas conflagrações de curiosidades". (BLOM, 2003, p.107). Um enciclopedismo que ao invés de se constituir das coisas da natureza, como em Aldrovandi; de conceitos e imagens incorpóreas, como em Camillo; ou de referências eruditas e esotéricas, como em Kircher, apresenta-se enquanto uma artificialia, um microcosmo de artefatos, de objetos fabricados, que funcionam como registros do que há de mais concreto na existência humana.

De coisas anônimas, que são de todos e de ninguém, compõe-se a enciclopédia de Bispo. Nela acumulam-se muitos saberes, sobretudo os advindos da experiência prosaica do artista, de sua vida à margem da vida, já que, para ele, as coisas que representam o mundo são também as que integram a grande narrativa de sua própria história pessoal. Cada coleção que a integra não deixa de ser, portanto, uma espécie de diário", mas um diário que abala a obviedade da cronologia e instaura a ordem do simultâneo, deflagrando uma temporalidade heterogênea, sem datas, que nunca se inscreve num instante determinado nem na perspectiva que este delimita. Nesse sentido, Bispo converte-se, através de seu trabalho, no que Borges, ao falar de seu personagem Funes, qualificou como o "solitário e lúcido espectador de um mundo multiforme, instantâneo e quase intoleravelmente preciso".(BORGES, 1998, p.545). Ao que se poderia acrescentar: $e$ inexato.

Se Georges Perec, no livro Pensar/classificar, afirma que "em um inventário não se escreve 'et cetera"'(PEREC, 2003, p.21), pode-se dizer que o inventário enciclopédico de Bispo desestabiliza essa cláusula, ao incluir em suas ordenações todas as sobras, tudo o que escapa das classificações previsíveis. Como explicar que, numa "vitrine" como a que recebeu o nome de "Sandálias e Peneiras", apareçam um quadro com uma foto de mulher e uma garrafa de plástico cheia de lascas de madeira? A que ordem pertencem as "FICHAS DA EMPRESA BANGU" que ocupam a extremidade direita da moldura

9 Segundo Italo Calvino, "toda coleção é um diário", movida pela "necessidade de transformar o transcorrer da própria existência em uma série de objetos salvos da dispersão ou em uma série de linhas escritas, cristalizadas fora do contínuo fluir dos pensamentos". Cf. (CALVINO, 1990, pp.16-17) (tradução minha) 
que sustenta os "Oito cetros" de misses? A enciclopédia de Arthur Bispo do Rosario faz, dessa forma, seus objetos coexistirem em um todo finito e organizado, mas a partir de uma lógica classificatória que não dispensa o que escapa dos limites da semelhança e da afinidade entre os itens inventariados. $O$ resultado de todo esse processo, que tem como função representar a complexa sintaxe do mundo, acaba por ser - no final das contas - a fragmentação dessa mesma sintaxe, a revelação da vertigem caótica da realidade circundante. E, por extensão, a revelação da própria realidade delirante do artista.

Os objetos e restos de coisas que integram a enciclopédia de Arthur Bispo do Rosário são, assim, testemunhos (aqui, no sentido arqueológico do termo) de sua história de confinamento. Por outro lado, apontam para um espaço sem demarcaçóes, para além da clausura. Como já disse Blanchot, se "para o homem medido e comedido, o quarto, o deserto e o mundo são lugares estritamente determinados", para o homem "labiríntico, votado ao erro de um empreendimento necessariamente um pouco mais longo que sua vida, o mesmo espaço será verdadeiramente infinito" (BLANCHOT, 1984, p.103). Disso Arthur Bispo do Rosario é um luminoso exemplo.

\section{Referências bibliográficas}

HIDALGO, Luciana. Artbur Bispo do Rosario - o senbor do labirinto. Rio de Janeiro: Rocco, 1996

FOUCAUIT, Michel. História da loucura. Trad. José Teixeira Neto. São Paulo: Perspectiva, 2005

ECO, Umberto, 1991, pp. 336-337. .ECO, Umberto. Sobre os espelbos e outros ensaios. Rio de Janeiro: Nova Fronteira.

MACIEL, Maria Esther. A memória das coisas. Rio de Janeiro: Lamparina, BARTHES, Roland. As pranchas da enciclopédia. Novos ensaios críticos / o grau zero da escritura. Trad. Heloysa de Lima Dantas et alli. São Paulo: Cultrix, 1974,

D'ALEMBERT. Discours Préliminaire de l'Encyclopédie. Site: http://art-bin. com/art/oalembert.html (última consulta: 17/03/2007).

POMBO, Olga. O projeto enciclopedista. In: POMBO, Olga et álli. Enciclopédia e intertexto. Lisboa: Duarte Reis, 2006.

LARA FILHO, Durval. Museu - de espelbo do mundo a espaço relacional. São Paulo: USP, 2005 (Dissertação de mestrado)

FOUCAULT, Michel. As palavras e as coisas. Trad. Salma Tannus. São Paulo: Martins Fontes, 1987

BLOM, Philipp. Ter e manter - uma bistória intima de colecionadores $e$ coleções. . Trad. Berilo Vargas. Rio de Janeiro: Record, 2003

HOCKE, Gustav R. Maneirismo: o mundo como labirinto. Trad. Clemente $\mathbf{R}$. Mahl. São Paulo: Perspectiva, 1986.

GODWN, Joscelyn. Athanasius Kircher - a renaissance man and quest for the lost knowledge. London: Thames and Hudson, 1979.

PEREC, Georges. Penser / classer. Paris: Seuil, 2003

BLANCHOT, Maurice. O livro por vir. Trad. Maria Regina Louro. Lisboa: Relógio d'Água, 1984

CAIVINO, Italo. Colección de arena. Trad. Aura Bernárdez. Madrid: Ediciones Siruela,1990, pp.16-17. 